\title{
Fatigue in liver disease: Pathophysiology and clinical management
}

\author{
Mark G Swain MD MSc FRCPC
}

MG Swain. Fatigue in liver disease: Pathophysiology and clinical management. Can J Gastroenterol 2006;20(3):181-188.

\begin{abstract}
Fatigue is the most commonly encountered symptom in patients with liver disease, and it has a significant impact on their quality of life. However, although some progress has been made with regard to the understanding of the processes which may generate fatigue in general, the underlying cause(s) of liver disease-associated fatigue remain incompletely understood. The present review describes recent advances which have been made in our ability to measure fatigue in patients with liver disease in the clinical setting, as well as in our understanding of potential pathways which are likely important in the pathogenesis of fatigue associated with liver disease. Specifically, experimental findings suggest that fatigue associated with liver disease likely occurs as a result of changes in neurotransmission within the brain. In conclusion, a reasonable approach to help guide in the management of the fatigued patient with liver disease is presented.
\end{abstract}

Key Words: Cholestasis; Fatigue; Hepatitis; Liver disease; Neurotransmitters; Therapy

Fatigue is a complex symptom that encompasses a range of F complaints including lethargy, malaise, lassitude and exhaustion. Chronic fatigue commonly occurs, affecting up to $20 \%$ of the population (1). Although the exact prevalence of fatigue in patients with chronic liver disease is somewhat variable in different studies and with different specific liver diseases, it is readily apparent that fatigue constitutes the most common complaint among this patient group (2-6). However, because of difficulties in defining and treating fatigue, this symptom is often overlooked or minimized by physicians caring for patients with liver disease. The prevalence of fatigue in patients with different forms of liver disease also appears to be quite variable. Specifically, cholestatic liver disease caused by primary biliary cirrhosis $(\mathrm{PBC})$, primary sclerosing cholangitis or drugs is commonly associated with fatigue $(2,3)$. In fact, fatigue in cholestatic patients can be the presenting symptom and occurs in $65 \%$ to $85 \%$ of patients $(2,3,7,8)$. Moreover, fatigue in $\mathrm{PBC}$ is considered to be the worst symptom in approximately $50 \%$ of patients, and is disabling in approximately $25 \%$ (7). Fatigue also has a significant impact on the health-related quality of life (HRQOL) of PBC patients (7-9).

The prevalence of fatigue in hepatitic liver diseases is less clearly defined. Fatigue is an integral component of the clinical presentation of patients with autoimmune hepatitis, often paralleling hepatic inflammation as determined by serum alanine aminotransferase measurements or liver biopsy findings,
La fatigue en cas de maladie hépatique : La physiopathologie et la prise en charge clinique

\begin{abstract}
La fatigue est le principal symptôme chez les patients atteints d'une maladie hépatique, et elle a des conséquences considérables sur leur qualité de vie. Cependant, même si certains progrès ont été réalisés quant à notre compréhension des processus généraux susceptibles de produire de la fatigue, les causes sous-jacentes de la fatigue associée à la maladie hépatique sont mal comprises. La présente analyse décrit les progrès récents accomplis dans notre capacité de mesurer la fatigue chez les patients atteints d'une maladie hépatique en milieu clinique, ainsi que dans notre compréhension des voies potentielles qui, selon toute probabilité, jouent un rôle important dans la pathogenèse de la fatigue associée à la maladie hépatique. Plus précisément, les observations expérimentales laissent supposer que la fatigue associée aux maladies hépatiques découle de modifications à la neurotransmission dans le cerveau. En conclusion, une démarche raisonnable pour orienter la prise en charge du patient atteint d'une maladie hépatique et de fatigue est présentée.
\end{abstract}

and responding usually quite rapidly to the institution of immunosuppressive therapy $(4,10,11)$. However, the overall prevalence of fatigue in patients with viral hepatitis is less clear. Acute presentations of viral hepatitis are often associated with feelings of fatigue or malaise, which gradually subside because the patient recovers clinically (eg, recovers from hepatitis A). However, the situation in patients with chronic viral hepatitis appears to be more controversial. Specifically, a significant proportion of patients with chronic hepatitis $\mathrm{C}$ who are followed in tertiary care centres, or who participate in clinical trials, complain of fatigue or decreased vitality, which has a direct negative impact on their HRQOL $(5,6,12)$. However, this high prevalence of fatigue does not appear to hold for patients infected with hepatitis $\mathrm{C}$ who are unaware of their diagnosis $(13,14)$. Moreover, the complaint of fatigue in hepatitis $\mathrm{C}$ patients does not appear to correlate with whether these patients are viremic (15). In contrast, patients chronically infected with hepatitis B appear to have HRQOL scores similar to those of healthy controls (12).

Recently, patients with hepatitis $\mathrm{C}$ have been reported to have subclinical findings of cognitive impairment and altered cerebral metabolism as reflected by magnetic resonance spectroscopy (16-18). The suggestion from these findings is that hepatitis $\mathrm{C}$ infection of the brain itself may lead to these changes $(17,19)$. However, it is unclear whether these central changes observed in hepatitis $\mathrm{C}$-infected patients are a direct

University of Calgary, Liver Unit, Health Sciences Centre, Calgary, Alberta

Correspondence: Dr Mark G Swain, 3330 Hospital Drive Northwest, Calgary, Alberta T2N 4N1. Telephone 403-220-8457, fax 403-270-0995, e-mail swain@ucalgary.ca

Received for publication August 22, 2005. Accepted October 12, 2005 


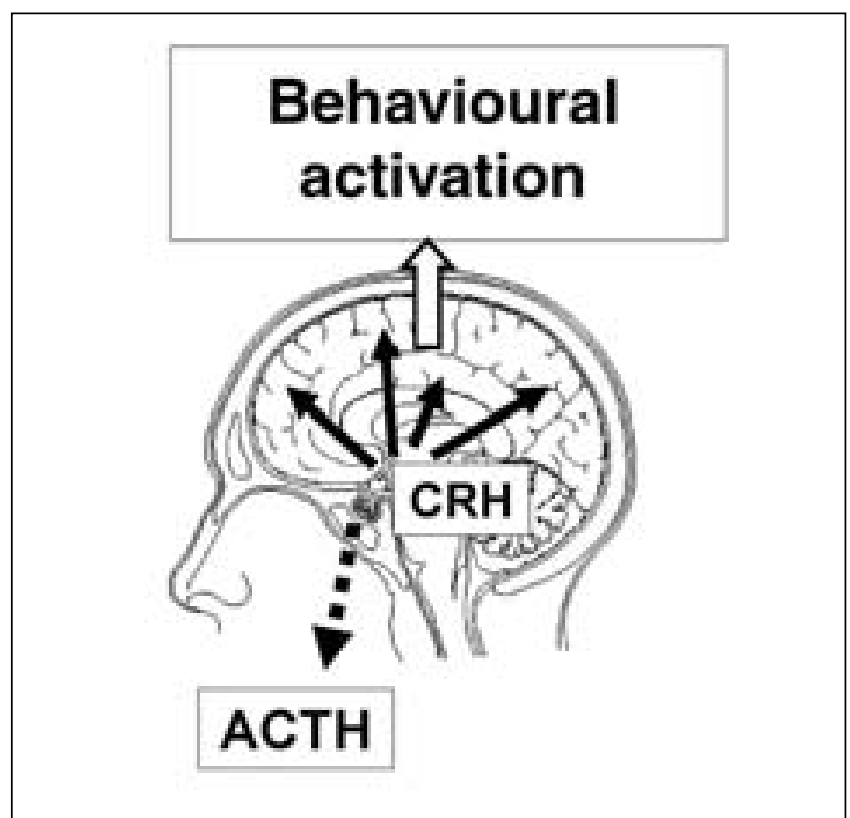

Figure 1) Corticotropin-releasing hormone (CRH) acts in its traditional role to stimulate adrenocorticotropic hormone (ACTH) release from the anterior pituitary gland. However, $\mathrm{CRH}$ release from nerve fibres projecting to areas within the brain stimulates behavioural activation and arousal

result of the hepatitis $\mathrm{C}$ virus within the brain, are related to the complex behavioural, social and mental sequelae associated with carrying a diagnosis of chronic hepatitis $\mathrm{C}$ infection or are related to the mode of acquisition of their hepatitis C (eg, intravenous drug abuse).

Therefore, any discussion of the pathophysiology and management of fatigue in the context of liver disease must take these observations into account.

\section{TYPES OF FATIGUE}

In any discussion of fatigue, it is imperative to differentiate central from peripheral fatigue. Peripheral fatigue relates to neuromuscular dysfunction and occurs with muscle overutilization and associated metabolic changes, and is classically manifested clinically by weakness $(20,21)$. This type of fatigue does not appear to be important in patients with liver disease in the absence of decompensated cirrhosis or liver failure. In contrast, central fatigue arises within the central nervous system (CNS) and is characterized by a difficulty in performing physical (and often mental) activities, which require self-motivation and responses to internal cues. Furthermore, central fatigue is often associated with a higher perceived effort when undertaking tasks (20). Therefore, by definition, central fatigue directly results from altered neurotransmission within the brain.

Typically, the complaint of central fatigue in the setting of any chronic disease, including liver diseases, does not correlate with traditional markers of disease activity or severity $(20,21)$. Moreover, central fatigue is often associated with other neuropsychiatric complaints also thought to be secondary to altered neurotransmission within the CNS; namely depression and anxiety $(20,21)$. This association of fatigue with depression and anxiety is commonly encountered in patients with cholestatic and hepatitic liver diseases $(6-8,22)$.
Given that central fatigue arises from changes in neurotransmitter systems within the brain, it is readily apparent that objective measurements of fatigue are problematic. Therefore, fatigue assessments in patients with liver disease have traditionally been performed using either general or specifically designed questionnaires (eg, Short Form-36 [12,15] versus Fatigue Impact Scale [23] or Fatigue Severity Scale [24]). By scoring a patient's answers to a given set of questions concerning fatigue, these questionnaires allow for an objective quantification or score of fatigue to be made. Changes in these scores have been used to determine worsening or improving in fatigue with therapeutic interventions in patients with liver disease.

\section{PATHOPHYSIOLOGY OF FATIGUE IN LIVER DISEASE}

The pathogenesis of fatigue in general is poorly understood and this holds true for fatigue in the setting of liver disease $(20,21,25)$. However, given that altered neurotransmission within the CNS drives central fatigue, and that central fatigue is the predominant issue in the setting of liver disease, any discussion of the possible etiology of fatigue in the context of liver disease must relate to these potential changes in neurotransmission within the brain $(21,25,26)$. Therefore, the discussion of the pathophysiology of fatigue in liver disease must incorporate two main concepts:

1. How does the diseased or damaged liver 'communicate' with the brain to cause changes in neurotransmission?

2. What specific changes in neurotransmission occur within the brain as a result of this 'communication', and how do these changes give rise to the genesis of central fatigue?

Moreover, this discussion must also be placed in the context that fatigue in patients with liver disease is manifest in the setting of a diagnosis often holding an uncertain outcome and often associated with societal taboos. Therefore, the diagnosis of chronic liver disease encompasses complex interactions among biological, psychosocial and behavioural processes, which can all significantly affect the clinical expression of fatigue in a given patient.

As outlined previously, the ultimate cause of central fatigue in patients with liver disease must entail alterations in neurotransmitter pathways within the brain. The specific neurotransmitter pathways that have received the greatest clinical and experimental attention as potentially causing central fatigue include pathways that are important in behavioural activation, arousal and locomotor activity (25-28). Brain areas important in this regard include the basal ganglia, brainstem, reticular and limbic systems and higher cortical centres $(20,25,26)$. The neurotransmitter systems that have been directly implicated in the genesis of central fatigue include the corticotropin-releasing hormone $(\mathrm{CRH})$, serotonin, noradrenaline and other neurotransmitter systems.

\section{$\mathrm{CRH}$}

CRH was initially identified as the factor released from the hypothalamus, which is the most potent activator of the hypothalamic-pituitary-adrenal axis. However, over the past three decades, it has become increasingly clear that CRHcontaining nerve fibres are widely distributed throughout the CNS and are intimately involved in arousal and behavioural activation (27,29-31; Figure 1). These observations have led to 
the hypothesis that defective release of $\mathrm{CRH}$ within the brain may be important in the development of central fatigue (3133). In an animal model of cholestatic liver disease, behaviours and physiological responses consistent with defective central CRH release have been documented (34-36). In addition, rats with experimental cholestasis demonstrate reduced hypothalamic CRH levels and increased CRH type 1 receptor expression, as well as enhanced sensitivity to the behavioural activating effects of centrally infused CRH (36); these findings are consistent with defective central CRH release playing an important role in cholestasis-associated fatigue. Moreover, clinical observations in patients with $\mathrm{PBC}$ also support this suggestion. Specifically, PBC patients demonstrate augmented adrenocorticotropic hormone release after intravenous CRH infusion, consistent with an upregulation of pituitary $\mathrm{CRH}$ receptors in these patients, possibly secondary to defective endogenenous CRH stimulation of their anterior pituitary glands (37). Of interest, defective central CRH release has also been implicated in central fatigue in patients with atypical depression and the chronic fatigue syndrome $(26,32)$.

\section{Serotonin}

Abnormal serotonergic neurotransmission has been commonly implicated in the development of altered behaviours including depression, anxiety and central fatigue (28). Serotonergic nerve fibres arise mainly within the dorsal raphe nucleus in the midbrain and project widely throughout the CNS $(28,38,39)$. Of interest, the serotonin and CRH neurotransmitter systems are known to be intimately interrelated $(38,40)$. Serotonin mediates its biological effects by activating a large number of receptor subtypes (41). However, the precise role played by serotonin in the generation of central fatigue remains unclear. It appears that serotonin released within the brain has a differential effect on the development of fatigue depending on whether exercise-induced fatigue or more classically defined central fatigue is being examined. Specifically, in rodents or athletes exercised to exhaustion, increased central serotonin levels appear to decrease exercise capacity $(42,43)$. These observations suggest that increased central serotonin levels may contribute to central fatigue. However, the applicability of findings regarding serotonin in the setting of exercise to exhaustion appears to be less relevant to fatigue in the setting of liver disease. Patients with chronic fatigue syndrome exhibit findings on pharmacological challenge that are consistent with increased central serotonin sensitivity due to decreased serotonin release (44). These observations provided the impetus to use serotonin reuptake inhibitors to treat patients with chronic fatigue syndrome, albeit with mixed results (45).

The serotonin neurotransmitter system has been studied in an animal model of cholestatic liver disease and the findings are consistent with a possible role of serotonin in liver diseaseassociated fatigue $(46,47)$. The 5-hydroxytryptamine $1 \mathrm{~A}$ $(5 \mathrm{HT})_{1 \mathrm{~A}}$ receptor subtype has been commonly linked to altered behaviours in humans and animals $(48,49)$. The $5 \mathrm{HT}_{1 \mathrm{~A}}$ receptor exists as an autoreceptor situated on cell bodies of serotonergic nerves originating in the midbrain dorsal raphe nucleus (50; Figure 2). Activation of these cell body serotonin autoreceptors in the midbrain results in decreased serotonin release from the distal nerve terminals that project throughout the CNS (48-50). However, $5 \mathrm{HT}_{1 \mathrm{~A}}$ receptors also exist postsynaptically within the brain. Activation of postsynaptic $5 \mathrm{HT}_{1 \mathrm{~A}}$ receptors typically exerts an inhibiting influence on

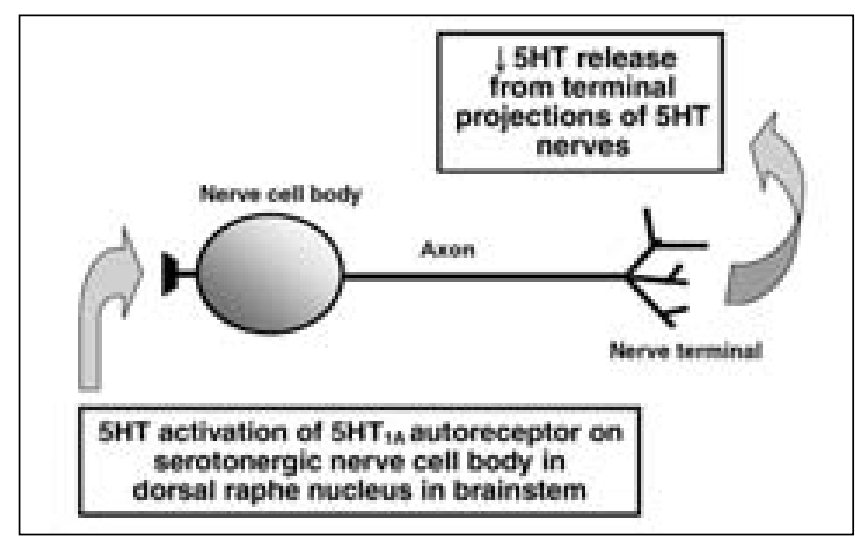

Figure 2) Serotonin-secreting nerves originate in the dorsal raphe nucleus within the midbrain and their axons project throughout the central nervous system. Activation of 5-hydroxytryptamine $1 \mathrm{~A}\left(5 \mathrm{HT}_{1 \mathrm{~A}}\right)$ autoreceptors located on serotonin nerve cell bodies within the raphe nucleus results in a decrease in serotonin release from nerve terminals at the distal projection sites of these serotonergic nerves. $\downarrow$ Decrease

neurons where they are located (48). Therefore, systemic administrations of a $5 \mathrm{HT}_{1 \mathrm{~A}}$ receptor agonist results in a net decrease in serotonin neurotransmission at all postsynaptic serotonin receptors except those of the $5 \mathrm{HT}_{1 \mathrm{~A}}$ subtype (48). Experimental results in cholestatic rats are consistent with increased sensitivity and the number of $5 \mathrm{HT}_{1 \mathrm{~A}}$ midbrain autoreceptors coupled with normal $5 \mathrm{HT}_{1 \mathrm{~A}}$ postsynaptic receptors elsewhere within the CNS $(46,47)$; these findings that would be expected to give rise to decreased central serotonin release as a potential contributor to central fatigue in cholestatic liver disease. In fact, this suggestion is supported by findings that the repeated administration of a $5 \mathrm{HT}_{1 \mathrm{~A}}$ receptor agonist, which desensitizes $5 \mathrm{HT}_{1 \mathrm{~A}}$ autoreceptors and increases central serotonin release into synapses where postsynaptic $5 \mathrm{HT}_{1 \mathrm{~A}}$ receptors are active, ameliorated fatigue-like behaviours in cholestatic rats (51). These observations suggest that the $5 \mathrm{HT}_{1 \mathrm{~A}}$ receptor may play an important role in the genesis of central fatigue in patients with liver disease.

More recently, $5 \mathrm{HT}_{3}$ receptor antagonists have been reported to improve fatigue in patients with the chronic fatigue syndrome (52), as well as in a patient with hepatitis Cinduced fatigue (53). Similar findings have been reported in preliminary experiments in cholestatic rats (54). Of note, in a recent clinical trial, the $5 \mathrm{HT}_{3}$ receptor antagonist ondansetron appeared to have a limited effect on fatigue in PBC patients, although the results of this study are difficult to interpret due to possible patient unblinding and a significant placebo effect (55). Therefore, the role played by serotoninactivating central $5 \mathrm{HT}_{3}$ receptors in the genesis of liver disease-associated fatigue remains unclear.

\section{Noradrenaline}

Noradrenaline is a classical neurotransmitter important in behavioural activation, especially in the context of acute stress (56). More important, hypofunctioning of noradrenalinecontaining nerve pathways within the brain has been implicated in the development of central fatigue (57). Specifically, reserpine, which depletes central calecholamine stores, is commonly associated with the development of fatigue and depression (58). Moreover, beta-blockers and alpha- 2 agonists frequently cause fatigue (58). Unfortunately, the role of altered noradrenaline 


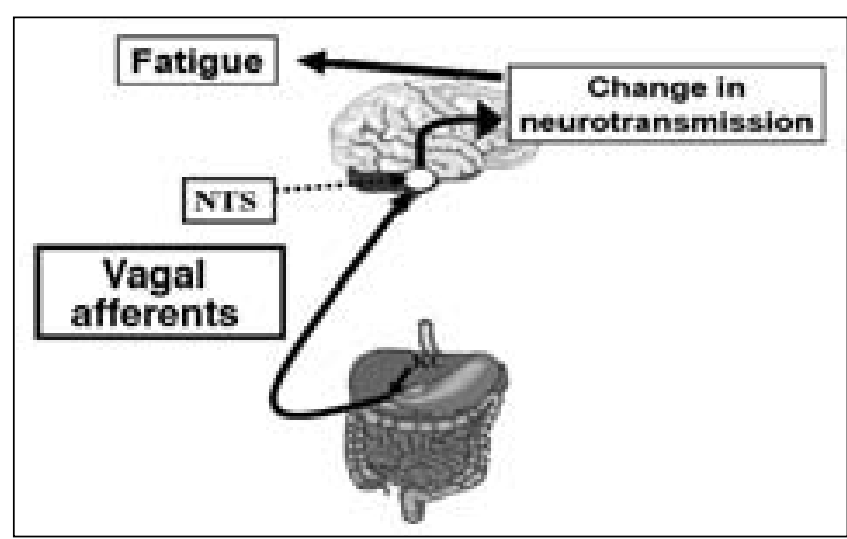

Figure 3) Neural transmission pathway for liver to brain signalling. Kupffer cells within the liver secrete proinflammatory mediators (eg, cytokines, prostaglandins) that activate vagal afferent nerves, which innervate the liver. Nerve impulses are then carried to the nucleus tractus solitarius (NTS) within the brainstem, which acts as a relay centre for the transmission of these impulses to areas throughout the brain. Stimulation of vagal afferent nerves can thereby result in alterations in neurotransmitter systems within the brain, which may give rise to central fatigue

neurotransmission in liver disease-associated fatigue remains completely unknown. However, an obvious patient population that could be studied includes cirrhotic patients taking betablockers as variceal bleed prophylaxis (59).

\section{Other neurotransmitters}

Numerous other neurotransmitter systems have also been implicated in the control of locomotor activity and behavioural activation, including the dopaminergic and cannabinoid systems $(60,61)$. However, no studies of the role of these neurotransmitter systems in liver disease-associated fatigue have been performed.

The obvious question that arises is, how do these alterations in central neurotransmission, which lead to fatigue, come about in the setting of liver disease? Although the answer to this question is still unclear, it likely involves specific communication pathways from the diseased liver to the brain, as well as nonspecific effects of liver disease acting in the context of a chronic stress for an individual (62).

Chronic stress can have profound behavioural effects (63). These changes in behaviour can include depression, anxiety and fatigue $(63,64)$. Moreover, this effect can be caused by physical, psychological or a combination of stressors, and these stressors have been implicated in changes in central neurotransmitter systems $(63,65,66)$. Of note, chronic stress in rodents can induce marked changes in neurotransmitter systems within the brain, which have been discussed earlier with regards to the genesis of central fatigue $(65,66)$. Furthermore, chronic liver disease can be viewed as both a physical and a psychological stressor. Although the physical stress of chronic liver disease is often relatively mild in the absence of cirrhosis or liver failure, the psychological impact of carrying a diagnosis of liver disease can be substantial because it directly involves social and professional interactions, and feelings of self-worth and fear. Certainly this 'indirect' pathway that relates to disease-labelling may contribute significantly to the development of central fatigue in patients who are aware of

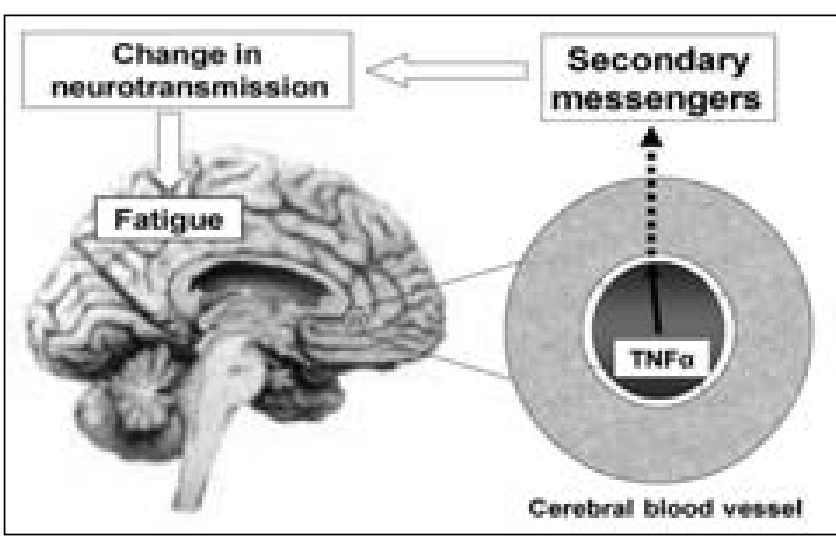

Figure 4) Humoral transmission pathway for liver to brain signalling. Substances released within the circulation in the setting of liver disease (eg, cytokines, including tumour necrosis factor-alpha [TNF $\alpha]$ ) activate the cerebral endothelial cells that make up the blood-brain barrier. Activated cerebral endothelial cells then secrete secondary messengers (eg, nitric oxide, prostaglandin $E_{2}$ ) into the brain parenchyma, which induce changes in central neurotransmitter systems, which give rise to central fatigue

their diagnosis (14,67-69). However, this does not account for the observation that a significant proportion of patients with liver disease presents to doctors specifically complaining of fatigue before a diagnosis of liver disease is made. Therefore, a 'direct' communication pathway between the liver and the brain appears to play an important role in fatigue genesis in the context of liver disease.

Traditionally, communication between the periphery (ie, outside the CNS) and the brain has been considered to involve two potential pathways: neural (ie, nerve projections; Figure 3 ) and/or humoral (ie, substances contained within the circulation; Figure 4) (70). In the setting of liver disease, either or both pathways may be activated.

The liver and peritoneum are richly innervated with afferent signals being carried to the brain in vagal and spinal nerve projections $(71,72)$. Activation of these nerves during inflammation in rodents stimulates areas of the brain important in regulating behavioural arousal and results in the development of fatigue-like behaviours (73-75). Moreover, these effects can be abolished by subdiaphragmatic vagotomy (76). However, patients who have recurrent liver inflammation following liver transplantation and therefore after complete hepatic denervation (eg, hepatitic C, PBC) often continue to experience fatigue $(77,78)$. These observations suggest that neural projections from the liver to the brain are less likely to contribute significantly to changes in CNS neurotransmitter systems that give rise to central fatigue in the setting of liver disease.

Communication between the diseased liver and the brain may also occur via mediators released into the circulation as a result of hepatic injury. In this regard, cytokines present within the circulation have received the greatest attention $(79,80)$. Specifically, the liver contains the largest population of fixed macrophages in the body, which represents an important source of cytokines found in the circulation $(79,80)$. Moreover, elevated circulating cytokine levels have commonly been documented in the setting of both cholestatic and hepatitic liver diseases (81-85). Furthermore, elevations in circulating 
cytokine levels, including interleukin-6, tumour necrosis factoralpha and interferons, commonly induce fatigue and lethargy (86-90). In addition, elevated plasma endotoxin levels have been documented in patients with liver disease (91-93), and endotoxin administration to humans and animals results in elevated circulating cytokine levels as well as the generation of malaise and lethargy (94). In support of inflammatory mediators in the circulation causing changes in central neurotransmission and inducing fatigue, the intravenous administration of cytokines or endotoxin in rodents results in altered central neurotransmitter levels, including those implicated in the genesis of central fatigue (eg, CRH, serotonin; [95-97]). Furthermore, in support of the hypothesis that endotoxin can alter central neurotransmission to change behaviour, a recent report (98) suggested that gut-derived endotoxin can precipitate hepatic encephalopathy in cirrhotic patients.

An obvious question that arises concerns how cytokines, which are large proteins, gain access to the CNS. Two potential theories have been put forward to explain this observation. First, there are areas of the brain that are devoid of an intact blood-brain barrier, which represent potential areas where large molecules such as cytokines could gain access to the CNS (99). Second, the cerebral endothelial cells, which form the basis of the blood-brain barrier, express a number of cytokine receptors and can be stimulated by cytokines within the circulation to produce a variety of secondary messengers (eg, nitric oxide, prostaglandin $\mathrm{E}_{2}$ ), which can then be secreted into brain parenchynal structures (100-102). Moreover, both prostaglandin $\mathrm{E}_{2}$ and nitric oxide are capable of inducing changes in central neurotransmitter systems $(79,80)$. In addition, circulating cytokines (via either of these mechanisms) can induce de novo synthesis and release of cytokines within the brain (from astroglia for example) $(79,80)$. In support of the hypothesis that liver disease is associated with altered central cytokine responses, rats with experimental cholestatic liver disease exhibit increased sensitivity to the generation of fatigue-like behaviours compared with controls when interleukin-1-beta is administered centrally (103). These findings suggest that cytokines entering, or being produced within, the brain, in the setting of liver disease can induce fatigue when present at levels that are without effect in healthy patients.

\section{MANAGEMENT OF FATIGUE IN PATIENTS WITH LIVER DISEASE}

\section{General approach}

Management of central fatigue associated with liver disease is complicated and hampered by a general lack of understanding of fatigue in general. Therefore, specific therapies are currently not available. However, many patients can benefit from a systematic approach. An important first step in this process is to rule out causes of fatigue that may be separate from the patient's liver disease. While meeting with a patient, specific questions should be asked with regard to symptoms of hypothyroidism, sleep patterns/behaviours, exercise, caffeine and alcohol ingestion, and life stresses. Moreover, a loss of motivation and pleasure in things that a patient would normally enjoy (ie, anhedonia), loss of interest in social activities, early morning awakenings, feelings of guilt and thoughts of suicide are important clues to the presence of depression and need to be directly addressed, and therapy instituted or psychiatric referral considered (20). In addition, a complete review of a patient's prescription medications (eg, beta-blockers, benzodiazepines, etc) as well as over-the-counter medications and health supplements should be undertaken. Finally, simple laboratory tests should be performed to exclude other possible causes of fatigue (eg, thyroid-stimulating hormone, calcium, creatinine, blood urea nitrogen, electrolytes, fasting blood sugar and magnesium).

\section{Modifying behavioural components to fatigue}

Significant central fatigue warrants lifestyle changes, which may include rest periods and reduced workloads (104,105). However, the maintenance of physical activity is of paramount importance. The natural inclination of patients with central fatigue is to decrease physical activity. However, decreased physical activity over time will lead to cardiovascular and muscular deconditioning, which then makes physical activity even more difficult $(104,105)$. Therefore, all patients need to be counselled with regard to maintaining an appropriate level of activity. In addition, an increase in activity should be attempted through the institution of a graded exercise program (106).

In many patients with liver disease and central fatigue, the degree and perpetuation of fatigue may be directly related to and influenced by a complex interaction of physiological, emotional, cognitive, behavioural and social factors (107). A patient's thoughts and beliefs (ie, cognitions) may contribute significantly to the maintenance of certain illness behaviours, including fatigue $(107,108)$. This concept has received the greatest attention in the setting of central fatigue related to chronic fatigue syndrome $(107,108)$. The idea is that psychological processes not only drive deleterious behavioural patterns, but also directly increase the perception of fatigue (108). Moreover, cognitive behavioural therapy is the only therapy of proven efficacy for patients with chronic fatigue syndrome (109). Therefore, cognitive behaviour therapy needs to be examined as a potential therapeutic modality for fatigue in patients with liver disease. Subjective sleep disturbance is commonly associated with fatigue in patients with liver disease $(8,110)$. Therefore, all fatigued liver disease patients need to be counselled with regard to proper sleep habits. However, any historical clues as to the presence of a specific sleep disorder (eg, sleep apnea) mandate the pursuit of formal sleep studies. In this vein, alcohol and caffeine should be limited. Moreover, any medications that may be contributing to fatigue should be discontinued if possible.

\section{Pharmacological interventions}

Specific pharmacological therapies directed at the physiological abnormalities that may underlie central fatigue in patients with liver disease are currently not available. Nonspecific CNS stimulants, including modafinil, have been used to treat central fatigue $(111,112)$; however, their use in patients with liver disease and fatigue has not been reported but may warrant further investigation, especially for patients with severe fatigue. Some patients respond to nocturnal therapy with low-dose amitriptyline, especially if poor sleep patterns are possibly contributing.

\section{CONCLUSIONS}

Fatigue is the most common symptom reported by patients with liver disease. Although the underlying pathogenesis of fatigue in liver disease is still poorly defined, it appears to involve changes in central neurotransmission, which result from signalling between the diseased liver and the brain. A 
better understanding of the pathways and the neurotransmitter systems involved may provide directed specific therapies for liver disease-associated fatigue.

ACKNOWLEDGEMENTS: Mark $G$ Swain is an Alberta Heritage Foundation for Medical Research Senior Scholar and a Canadian Institutes of Health Research Investigator.

\section{REFERENCES}

1. Adams RD, Victor M, Ropper AH. Fatigue, asthenia, anxiety and depressive reactions. In: Adams RD, Victor M, Ropper AH, eds. Principles of Neurology, 6th edn. New York: McGraw-Hill, 1997:497-507.

2. Kumar D, Tandon RK. Fatigue in cholestatic liver disease a perplexing symptom. Postgrad Med J 2002;78:404-7.

3. Milkiewicz P, Heathcote EJ. Fatigue in chronic cholestasis. Gut 2004;53:475-7.

4. Obermayer-Straub P, Strassburg CP, Manns MP. Autoimmune hepatitis. J Hepatol 2000;32(Suppl 1):181-97.

5. Kenny-Walsh E; Irish Hepatology Research Group. Clinical outcomes after hepatitis $\mathrm{C}$ infection from contaminated anti-D immune globulin. N Engl J Med 1999;340:1228-33.

6. Poynard T, Cacoub P, Ratziu V, et al. Fatigue in patients with chronic hepatitis C. J Viral Hepat 2002;9:295-303.

7. Huet PM, Deslauriers J, Tran A, Faucher C, Charbonneau J. Impact of fatigue on the quality of life in patients with primary biliary cirrhosis. Am J Gastroenterol 2000;95:760-7.

8. Cauch-Dudek K, Abbey S, Stewart DE, Heathcote EJ. Fatigue in primary biliary cirrhosis. Gut 1998;43:705-10.

9. Younossi ZM, Boparai N, Price LL, Kiwi ML, McCormick M, Guyatt G. Health-related quality of life in chronic liver disease: The impact of type and severity of liver disease. Am J Gastroenterol 2001;96:2199-205.

10. Ferrari R, Pappas G, Agostinelli D, et al. Type 1 autoimmune hepatitis: Patters of clinical presentations and differential diagnosis of the 'acute' type. QJM 2004;97:407-12.

11. Czaja AJ, Freese DK. Diagnosis and treatment of autoimmune hepatitis. Hepatology 2002;36:479-97.

12. Foster GR, Goldin RD, Thomas HC. Chronic hepatitis C virus infection causes a significant reduction in quality of life in the absence of cirrhosis. Hepatology 1998;27:209-12.

13. Wessely S, Pariante C. Fatigue, depression and chronic hepatitis $C$ infection. Psychol Med 2002;32:1-10.

14. Rodger AJ, Jolley D, Thompson SC, Lanigan A, Crofts N. The impact of diagnosis of hepatitis $\mathrm{C}$ virus on quality of life. Hepatology 1999;30:1299-301.

15. Coughlan B, Sheehan J, Hickey A, Crowe J. Psychological well-being and quality of life in women with an iatrogenic hepatitis $\mathrm{C}$ infection. Br J Health Psychol 2002; 7:105-16.

16. Kramer L, Bauer E, Funk G, et al. Subclinical impairment of brain function in chronic hepatitis $\mathrm{C}$ infection. J Hepatol 2002;37:349-54.

17. Forton DM, Allsop JM, Main J, Foster GR, Thomas HC, Taylor-Robinson SD. Evidence for a cerebral effect of the hepatitis C virus. Lancet 2001;358:38-9.

18. Weissenborn K, Krause J, Bokemeyer M, et al. Hepatitis C virus infection affects the brain-evidence from psychometric studies and magnetic resonance spectroscopy. J Hepatol 2004;41:845-51.

19. Morgello $S$. The nervous system and hepatitis $C$ virus. Semin Liver Dis 2005;25:118-21.

20. Chaudhuri A, Behan PO. Fatigue in neurological disorders. Lancet 2004:363:978-88

21. Swain MG. Fatigue in chronic disease. Clin Sci (Lond) 2000;99:1-8.

22. McDonald J, Jayasuriya R, Bindley P, Gonsalvez C, Gluseska S. Fatigue and psychological disorders in chronic hepatitis C. J Gastroenterol Hepatol 2002;17:171-6.

23. Schwartz JE, Jandorf L, Krupp LB. The measurement of fatigue: A new instrument. J Psychosom Res 1993;37:753-62.

24. Fisk J, Ritvo PG, Ross L, Haase DA, Marrie TJ, Schlech WF. Measuring the functional impact of fatigue: Initial validation of the fatigue impact scale. Clin Infect Dis 1994;18(Suppl 1):S79-83.

25. Bearn J, Wessely S. Neurobiological aspects of the chronic fatigue syndrome. Eur J Clin Invest 1994;24:79-90.
26. Crofford LJ, Demitrack MA. Evidence that abnormalities of central neurohormonal systems are key to understanding fibromyalgia and chronic fatigue syndrome. Rheum Dis Clin North Am 1996;22:267-84.

27. Koob GF. Corticotropin-releasing factor, norepinephrine, and stress. Biol Psychiatry 1999;46:1167-80

28. Lucki I. The spectrum of behaviors influenced by serotonin. Biol Psychiatry 1998;44:151-62.

29. Swanson LW, Sawchenko PE, Rivier J, Vale WW. Organization of ovine corticotropin-releasing factor immunoreactive cells and fibers in the rat brain: An immunohistological study. Neuroendocrinology 1983;36:165-86

30. Koob GF, Heinrichs SC, Pich EM, et al. The role of corticotropinreleasing factor in behavioural responses to stress. Ciba Found Symp 1993;172:277-89.

31. Sutton RE, Koob GF, Le Moal M, Rivier J, Vale W. Corticotropinreleasing factor produces behavioural activation in rats. Nature 1982;297:331-3.

32. Gold PW, Chrousos GP. The endocrinology of melancholic and atypical depression: Relation to neurocircuitry and somatic consequences. Proc Assoc Am Phys 1998;111:22-34.

33. Clauw DJ, Chrousos GP. Chronic pain and fatigue syndromes: Overlapping clinical and neuroendocrine features and potential pathogenic mechanisms. Neuroimmunomodulation 1997;4:134-53.

34. Swain MG, Patchev V, Vergalla J, Chrousos G, Jones EA. Suppression of hypothalamic-pituitary-adrenal axis responsiveness to stress in a rat model of acute cholestasis. J Clin Invest 1993;91:1903-8.

35. Swain MG, Maric M. Defective corticotropin-releasing hormone mediated neuroendocrine and behavioral responses in cholestatic rats: Implications for cholestatic liver disease-related sickness behaviors. Hepatology 1995;22:1560-4.

36. Burak KW, Le T, Swain MG. Increased sensitivity to the locomotoractivating effects of corticotropin-releasing hormone in cholestatic rats. Gastroenterology 2002;122:681-8.

37. Swain MG, Mogiakou MA, Bergassa NV, Chrousos GP. Facilitation of $\mathrm{ACTH}$ and cortisol responses to corticotropin-releasing hormone $(\mathrm{CRH})$ in patients with primary biliary cirrhosis. Hepatology 1994;20:A197.

38. Hanley NR, Van de Kar LD. Serotonin and the neuroendocrine regulation of the hypothalamic-pituitary-adrenal axis in health and disease. Vitam Horm 2003;66:189-255.

39. Abrams JK, Johnson PL, Hollis JH, Lowry CA. Anatomic and functional topography of the dorsal raphe nucleus. Ann N Y Acad Sci 2004;1018:46-57.

40. Buller KM. Neuroimmune stress responses: Reciprocal connections between the hypothalamus and the brainstem. Stress 2003;6:11-7

41. Roth BL. Multiple serotonin receptors: Clinical and experimental aspects. Ann Clin Psychiatry 1994;6:67-78.

42. Bailey SP, Davis JM, Ahlborn EN. Neuroendocrine and substrate responses to altered brain 5-HT activity during prolonged exercise to fatigue. J Appl Physiol 1993;74:3006-12.

43. Wilson WM, Maughan RJ. Evidence for a possible role of 5-hydroxytryptamine in the genesis of fatigue in man: Administration of paroxetine, a 5-HT re-uptake inhibitor, reduces the capacity to perform prolonged exercise. Exp Physiol 1992;77:921-4.

44. Bakheit AM, Behan PO, Dinan TG, Gray CE, O'Keane V. Possible upregulation of hypothalamic 5-hydroxytryptamine receptors in patients with postviral fatigue syndrome. BMJ 1992;304:1010-2

45. Goldenberg D, Mayskiy M, Mossey C, Ruthazer R, Schmid C. A randomized, double-blind crossover trial of fluoxetine and amitriptyline in the treatment of fibromyalgia. Arthritis Rheum 1996;39:1852-9.

46. Burak KW, Le T, Swain MG. Increased midbrain 5-HT1A receptor number and responsiveness in cholestatic rats. Brain Res 2001;892:376-9.

47. Celik T, Goren MZ, Cinar K, et al. Fatigue of cholestasis and the serotonergic neurotransmitter system in the rat. Hepatology 2005;41:731-7.

48. Blier P, Ward NM. Is there a role for 5-HT1A agonists in the treatment of depression? Biol Psychiatry 2003;53:193-203.

49. Rueter LE, Fornal CA, Jacobs BL. A critical review of 5-HT brain microdialysis and behavior. Rev Neurosci 1997;8:117-37.

50. Riad M, Watkins KC, Doucet E, Hamon M, Descarries L. Agonistinduced internalization of serotonin-1a receptors in the dorsal raphe nucleus (autoreceptors) but not hippocampus (heteroreceptors). J Neurosci 2001;21:8378-86.

51. Swain MG, Maric M. Improvement in cholestasis-associated fatigue 
with a serotonin receptor agonist using a novel rat model of fatigue assessment. Hepatology 1997;25:291-4.

52. Spath M, Welzel D, Farber L. Treatment of chronic fatigue syndrome with 5-HT3 receptor antagonists - preliminary results. Scand J Rheumatol Suppl 2000;113:72-7.

53. Jones EA. Relief from profound fatigue associated with chronic liver disease by long-term ondansetron therapy. Lancet 1999;354:397.

54. Swain MG, Le T, Ho W, Sharkey KA. Fatigue-like behavior is significantly improved by the 5-HT3 receptor antagonist tropisetron in cholestatic rats. Hepatology 2004;40:A292.

55. Theal JJ, Toosi MN, Girlan L, et al. A randomized, controlled crossover trial of ondansetron in patients with primary biliary cirrhosis and fatigue. Hepatology 2005;41:1305-12.

56. Berridge CW, Waterhouse $\mathrm{BD}$. The locus coeruleus-noradrenergic system: Modulation of behavioral state and state-dependent cognitive processes. Brain Res Brain Res Rev 2003;42:33-84

57. Gold PW, Chrousos GP. The endocrinology of melancholic and atypical depression: Relation to neurocircuitry and somatic consequences. Proc Assoc Am Physicians 1999;111:22-34.

58. Webster J, Koch HF. Aspects of tolerability of centrally acting antihypertensive drugs. J Cardiovasc Pharmacol 1996;27(Suppl 3):S49-54.

59. Vlachogiannakos J, Goulis J, Patch D, Burroughs AK. Review article: Primary prophylaxis for portal hypertensive bleeding in cirrhosis. Aliment Pharmacol Ther 2000;14:851-60.

60. Tzschentke TM. Pharmacology and behavioral pharmacology of the mesocortical dopamine system. Prog Neurobiol 2001;63:241-320.

61. Iversen L. Cannabis and the brain. Brain 2003;126:1252-70.

62. Shanks S, Harbuz MS, Jessop DS, Perks P, Moore PM, Lightman SL. Inflammatory disease as chronic stress. Ann N Y Acad Sci 1998;840:599-607.

63. Chrousos GP, Gold PW. The concepts of stress and stress system disorders. Overview of physical and behavioral homeostasis. JAMA 1992;267:1244-52. (Erratum in 1992;268:200).

64. Korte SM, Koolhaas JM, Wingfield JC, McEwen BS. The Darwinian concept of stress: Benefits of allostasis and costs of allostatic load and the trade-offs in health and disease. Neurosci Biobehav Rev 2005;29:3-38.

65. Tsigos C, Chrousos GP. Hypothalamic-pituitary-adrenal axis, neuroendocrine factors and stress. J Psychosom Res 2005;53:865-71.

66. McEwen BS. The neurobiology of stress: From serendipity to clinical relevance. Brain Res 2000;886:172-89.

67. Cordoba J, Reyes J, Esteban JI, Hernandez JM. Labeling may be an important cause of reduced quality of life in chronic hepatitis C. Am J Gastroenterol 2003;98:226-7.

68. Suurmeijer TP, Reuvekamp MF, Aldenkamp BP. Social functioning, psychological functioning, and quality of life in epilepsy. Epilepsia 2001;42:1160-8.

69. Grassi L, Satriano J, Serra A, et al. Emotional stress, psychosocial variables and coping associated with hepatitis $C$ virus and human immunodeficiency virus infections in intravenous drug users. Psychother Psychosom 2002;71:342-9.

70. Blatteis CM. The afferent signalling of fever. J Physiol 2000;526:470.

71. Adachi A. Projection of the hepatic vagal nerve in the medulla oblongata. J Auton Nerv Syst 1984;10:287-93.

72. Magni F, Carobi C. The afferent and preganglionic parasympathetic innervation of the rat liver, demonstrated by the retrograde transport of horseradish peroxidase. J Auton Nerv Syst 1983;8:237-60.

73. Wan W, Wetmore L, Sorensen CM, Greenberg AH, Nance DM. Neural and biochemical mediators of endotoxin and stress-induced c-fos expression in the rat brain. Brain Res Bull 1994;34:7-14.

74. Goehler LE, Gaykema RP, Hansen MK, Anderson K, Maier SF, Watkins LR. Vagal immune-to-brain communication: A visceral chemosensory pathway. Auton Neurosci 2000;85:45-59.

75. Konsman JP, Luheshi GN, Bluthe RM, Dantzer R. The vagus nerve mediates behavioural depression, but not fever, in response to peripheral immune signals; a functional anatomical analysis. Eur J Neurosci 2000;12:4434-46.

76. Gaykema RP, Dijkstra I, Tilder FJ. Subdiaphragmatic vagotomy supresses endotoxin-induced activation of the hypothalamic corticotropin-releasing hormone neurons and ACTH secretion. Endocrinology 1995;136:4717-20.

77. O'Carroll RE, Couston M, Cossar J, Masterton G, Hayes PC. Psychological outcome and quality of life following liver transplantation: A prospective, national, single-center study. Liver Transpl 2003;9:712-20.

78. Belle SH, Porayko MK, Hoofnagle JH, Lake JR, Zetterman RK.
Changes in quality of life after liver transplantation among adults. National Institute of Diabetes and Digestive and Kidney Diseases (NIDDK) Liver Transplantation Database (LTD). Liver Transpl Surg 1997;3:93-104

79. Turnbull AV, Rivier CL. Regulation of the hypothalamic-pituitaryadrenal axis by cytokines: Actions and mechanisms of action. Physiol Rev 1999;79:1-71

80. Licinio J, Wong ML. Pathways and mechanisms for cytokine signaling of the central nervous system. J Clin Invest 1997;100:2941-7.

81. Tilg H, Wilmer A, Vogel W, et al. Serum levels of cytokines in chronic liver diseases. Gastroenterology 1992;103:264-74.

82. Eriksson AS, Gretzer C, Wallerstedt S. Elevation of cytokines in peritoneal fluid and blood in patients with liver cirrhosis. Hepatogastroenterology 2004;51:505-9.

83. Tilg H. Cytokines and liver diseases. Can J Gastroenterol 2001;15:661-8

84. Bemelmans MH, Gouma DJ, Greve JW, Buurman WA. Cytokines tumor necrosis factor and interleukin-6 in experimental biliary obstruction in mice. Hepatology 1992;15:1132-6.

85. Mizuhara H, O’Neill E, Seki N, et al. T cell activation-associated hepatic injury: Mediation by tumor necrosis factors and protection by interleukin-6. J Exp Med 1994;179:1529-37.

86. Vollmer-Conna U, Fazou C, Cameron B, et al. Production of proinflammatory cytokines correlates with the symptoms of acute sickness behaviour in humans. Psychol Med 2004;34:1289-97.

87. Kerr JR, Tyrrell DA. Cytokines in parvovirus B19 infection as an aid to understanding chronic fatigue syndrome. Curr Pain Headache Rep 2003; 7:333-41.

88. Mullington JM, Hinze-Selch D, Pollmacher TO. Mediators of inflammation and their interaction with sleep: Relevance for chronic fatigue syndrome and related conditions. Ann N Y Acad Sci 2001;933:201-10.

89. Taylor JL, Grossberg SE. The effects of interferon-alpha on the production and action of other cytokines. Semin Oncol 1998;25(Suppl 1):23-9.

90. Schuler M, Bruntsch U, Spath-Schwalbe E, et al. Lack of efficacy of recombinant human interleukin- 6 in patients with advanced renal cell carcinoma: Results of a phase II study. Eur J Cancer 1998;34:754-6

91. Kaser A, Ludwiczek O, Waldenberger P, Jaschke W, Vogel W, Tily H. Endotoxin and its binding proteins in chronic liver disease: The effect of transjugular intrahepatic portosystemic shunting. Liver 2002;22:380-7.

92. Caradonna L, Mastronardi ML, Magrone T, et al. Biological and clinical significance of endotoxemia in the course of hepatitis $\mathrm{C}$ virus infection. Curr Pharm Des 2002;8:995-1005.

93. Yamamoto Y, Sezai S, Sakurabayashi S, Hirano M, Kamisaka K, Oka H. A study of endotoxaemia in patients with primary biliary cirrhosis. J Int Med Res 1994;22:95-9.

94. Dantzer R. Cytokine-induced sickness behavior: Where do we stand? Brain Behav Immun 2001;15:7-24.

95. Suda T, Tozawa F, Ushiyama T, Sumimoto T, Yamada M, Demura H. Interleukin-1 stimulates corticotropin-releasing factor gene expression in rat hypothalamus. Endocrinology 1990;126:1223-8.

96. Linthorst AC, Reul JM. Brain neurotransmission during peripheral inflammation. Ann N Y Acad Sci 1998;840:139-52.

97. Hayley S, Lacosta S, Merali Z, van Rooijen N, Anisman H. Central monoamine and plasma corticosterone charges induced by a bacterial endotoxin: Sensitization and cross-sensitization effects. Eur J Neurosci 2001;13:1155-65.

98. Shawcross DL, Davies NA, Williams R, Jalan R. Systemic inflammatory response exacerbates the neuropsychological effects of induced hyperammonemia in cirrhosis. J Hepatol 2004;40:247-54.

99. McKinley MJ, McAllen RM, Davern P, et al. The sensory circumventricular organs of the mammalian brain. Adv Anat Embryol Cell Biol 2003;172:III-Xii,1-122.

100. Vallieres L, Rivest S. Regulation of the genes encoding interleukin-6, its receptor, and gp130 in the rat brain in response to the immune activation lipopolysaccharide and proinflammatory cytokine interleukin-1beta. J Neurochem 1997;69:1668-83.

101. Van Dam AM, De Vries HE, Kuiper J, et al. Interleukin-1 receptors on rat brain endothelial cells: A role in neuroimmune interaction? FASEB J 1996;10:351-6.

102. Nadeau S, Rivest S. Effects of circulating tumor necrosis factor on the neuronal activity and expression of the genes encoding the 
tumor necrosis factor receptors ( $\mathrm{p} 55$ and $\mathrm{p} 75$ ) in the rat brain: A view from the blood-brain barrier. Neuroscience 1999;93:1449-64.

103. Swain MG, Beck P, Rioux K, Le T. Augmented interleukin-1betainduced depression of locomotor activity in cholestatic rats. Hepatology 1998:28:1561-5.

104. Cook NF, Boore JR. Managing patients suffering from acute and chronic fatigue. Br J Nurs 1997;6:811-5.

105. Graydon JE, Bubela N, Irvine D, Vincent L. Fatigue-reducing strategies used by patients receiving treatment for cancer. Cancer Nurs 1995;18:23-8.

106. Wearden AJ, Morriss RK, Mullis R, et al. Randomised, double-blind, placebo-controlled treatment trial of fluoxetine and graded exercise for chronic fatigue syndrome. Br J Psychiatry 1998;172:485-90. (Erratum in 1998;173:89).

107. Sharpe M. Cognitive behavior therapy for chronic fatigue syndrome: Efficacy and implications. Am J Med 1998;105(Suppl 3A):104S-9S.
108. Fry AM, Martin M. Fatigue in the chronic fatigue syndrome: A cognitive phenomenon. J Psychosom Res 1996;41:415-26.

109. Whiting P, Bagnall AM, Sowden AJ, Cornell JE, Mulrow CD, Ramirez G. Interventions for the treatment and management of chronic fatigue syndrome: A systematic review. JAMA 2001;286:1360-8. (Erratum in 2002;287:1401).

110. Cordoba J, Cabrera J, Lataif L, Penev P, Zee P, Blei AT. High prevalence of sleep disturbance in cirrhosis. Hepatology 1998;27:339-45.

111. Becker PM, Schwartz JR, Feldman NT, Hughes RJ. Effect of modafinil on fatigue, mood, and health-related quality of life in patients with narcolepsy. Psychopharmacology (Berl) 2004;171:133-9.

112. Rammohan KW, Rosenberg JH, Lynn DJ, Blumenfeld AM, Pollak CP, Nagaraja HN. Efficacy and safety of modafinil (Provigil) for the treatment of fatigue in multiple sclerosis: A two center phase 2 study. J Neurol Neurosurg Psychiatry 2002;72:179-83. 


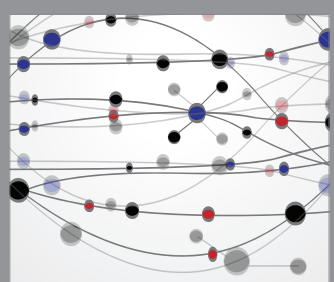

The Scientific World Journal
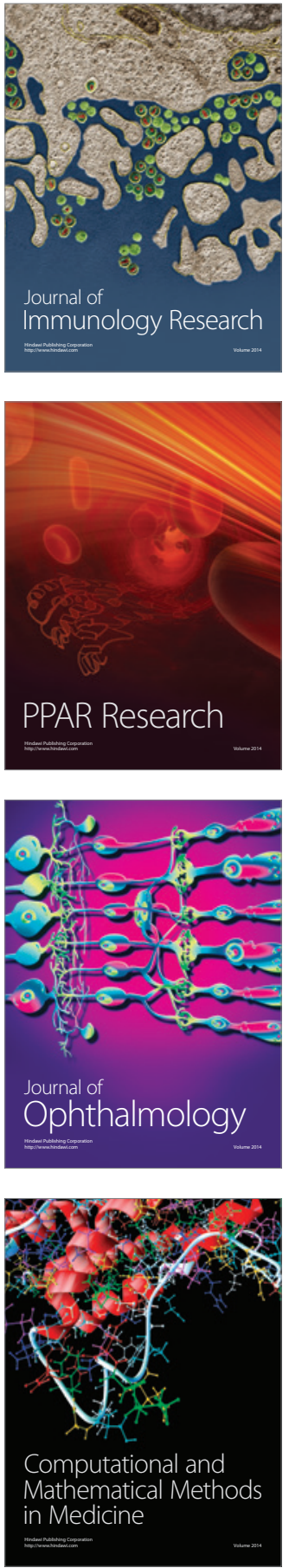

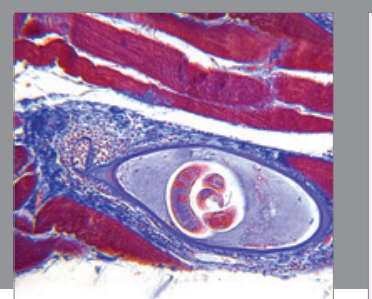

Gastroenterology Research and Practice

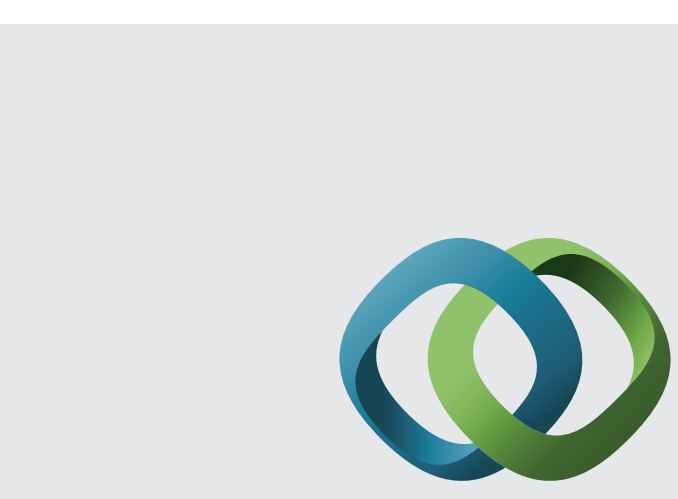

\section{Hindawi}

Submit your manuscripts at

http://www.hindawi.com
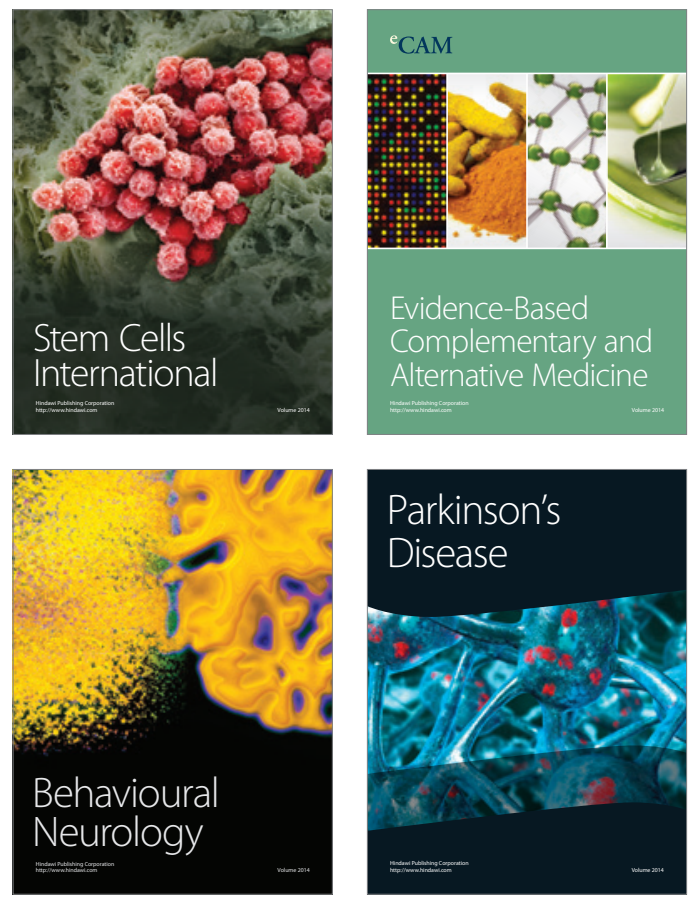
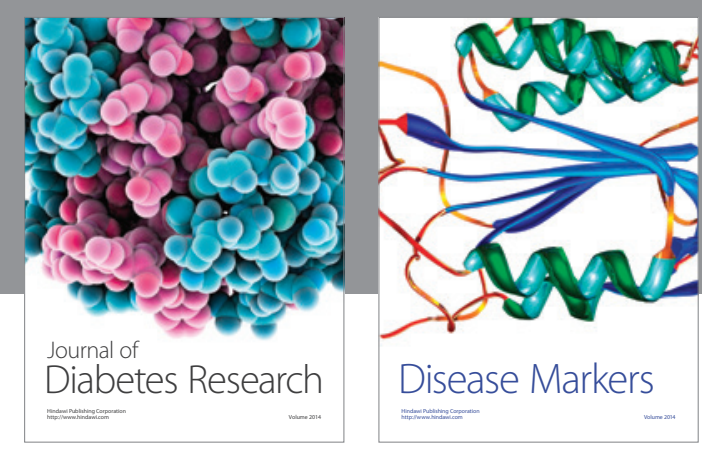

Disease Markers
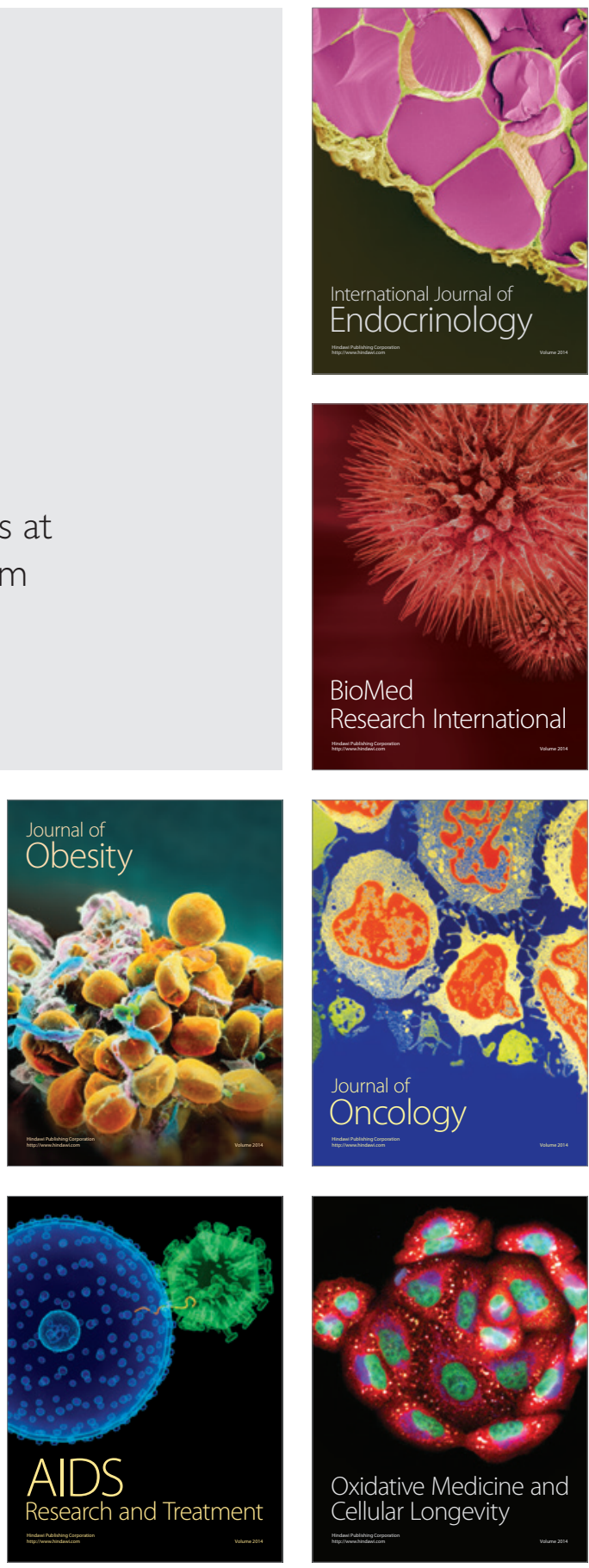